\title{
RANCANGAN D-OPTIMAL MODEL MICHAELIS MENTEN DAN EMAX DENGAN MATLAB
}

\author{
Tatik Widiharih $^{1}$, Sri Haryatmi ${ }^{2}$, Gunardi ${ }^{3}$, Yuciana Wilandari ${ }^{4}$ \\ ${ }^{1}$ Jurusan Statistika FSM UNDIP, widiharih@gmail.com \\ ${ }^{2}$ Jurusan Matematika FMIPA UGM, s_kartiko@yahoo.com \\ 2Jurusan Matematika FMIPA UGM, gunardi@ugm.ac.id \\ ${ }^{1}$ Jurusan Statistika FSM UNDIP, yuciana.wilandari@gmail.com
}

\begin{abstract}
Michaelis Menten and Emax models are widely used in chemistry, pharmacokinetics and pharmacodynamics areas. D-optimal criteria is criteria with the purpuse to minimize the variance of the estimator of parameters in the model. In this paper will discuss the D-optimal design for Michaelis Menten and Emax models with homoscedastics error assumtion. Determination of D-optimal designs based on Generalied Equivalence Theorem Kiefer-Wolvowitz. We used minimally supported design with the proportion of each design point is uniform, lower bound of design region is design point and the others are interior points.
\end{abstract}

Keywords: D-optimal, Michaelis Menten, Emax, Minimally Supported Design, Homoscedastics

\section{Pendahuluan}

Sebelum melakukan penelitian, peneliti membuat rancangan yang sesuai dengan permasalahan yang dihadapi. Masalah yang sering muncul adalah bagaimana menentukan titik-titik rancangan yang akan dicobakan sehingga memenuhi kriteria yang telah ditetapkan oleh peneliti. Salah satu kriteria tersebut adalah kriteria optimal. Optimal bisa berarti mempunyai galat minimum, biaya minimum, bias minimum, variansi minimum dan sebagainya sesuai dengan permasalahan dan tuuan yang telah ditetapkan.

Kriteria D-optimal merupakan kriteria dengan tujuan meminimalkan variansi dari penduga parameter dalam model. Bila variansi dari penduga parameter kecil diharapkan model akan signifikan (hipotesis yang menyatakan nilai parameter sama dengan nol ditolak). Pada awalnya kriteria D-optimal digunakan untuk model regresi linear. Selanjutnya dikembangkan untuk model nonlinear dengan menggunakan ekspansi deret Taylor ${ }^{[1],[9]}$. Model nonlinear banyak diaplikasikan pada berbagai bidang terutama untuk memodelkan kurva pertumbuhan.

Model regresi nonlinear yang banyak digunakan diantaranya model sigmoid. Rancangan D-optimal untuk model nonlinear telah banyak dilakukan diantaranya Dette and Pepelyshev ${ }^{[2]}$ menggunakan model sigmoidal untuk empat macam model yaitu model regresi eksponensial dengan bentuk $y=\alpha-\beta e^{-\lambda x}+\varepsilon$, model regresi Weibull dengan bentuk $y=\alpha-\beta e^{-\lambda x^{\gamma}} \varepsilon$, model regresi logistic dengan bentuk $y=\frac{\alpha}{\alpha+\beta e^{-\lambda x}}+\varepsilon$, dan model regresi Richards dengan bentuk $y=\frac{\alpha}{\left(\alpha+\beta e^{-\lambda x}\right)^{\gamma}}+\varepsilon \cdot \mathrm{Li}^{[5]}$ menggunakan model regresi Gompertz dengan bentuk $y=\beta$.exp $\left(-e^{-\gamma(x-\tau)}\right)$, yang diaplikasikan pada bidang biologi.

Model Michaelis Menten dan Emax banyak diaplikasikan pada bidang kimia, pharmakokinetik dan pharmakodinamik. Jericevic and Kuster ${ }^{[8]}$ menggunakan model Michaelis Menten untuk menggambarkan hubungan antara konsentrasi dari substrate dan 
kecepatan reaksi. Holford ${ }^{[7]}$ menggunakan model EMAX untuk menggambarkan hubungan antara konsentrasi dari receptor dan pengaruh dari sejenis obat. Kurva dari model Michaelis Menten dan Emax berbentuk huruf S.

Rancangan D-optimal untuk model kurva pertumbuhan berbentuk huruf $\mathrm{S}$ juga telah diteliti diantaranya Li and Majumdar ${ }^{[4]}$ menggunakan fungsi Logistik dengan tiga dan empat parameter, dan rancangan yang digunakan merupakan rancangan minimal. Fang and Hedayat ${ }^{[3]}$ menggunakan model Emax dengan satu komponen melalui pendekatan analisis fungsional. Selanjutnya $\mathrm{Li}^{[5]}$ menggunakan fungsi Gompertz dengan dua dan tiga parameter. Rancangan yang digunakan adalah rancangan minimal dan semua titik rancangan berupa titik interior dari daerah rancangan. Rancangan $D$-optimal untuk model kurva pertumbuhan tumor telah diteliti oleh Li and Balakrishnan ${ }^{[6]}$. Model yang digunakan dikenal dengan model LINEX dan REGROWTH. Rancangan yang digunakan adalah rancangan minimal dengan titik-titik rancangan semua merupakan titik interior dari daerah rancangan.

Terinspirasi untuk kurva pertumbuhan berbentuk huruf S, sebagai alternatif digunakan fungsi Morgan Mercer Flodin (MMF). Pada model ini penulis telah melakukan penelitian untuk model MMF tanpa intercept dengan pendekatan konsep sistem Tchebysheff $^{[10]}$. Selanjutnya penelitian rancangan D-optimal untuk model MMF tiga parameter telah juga dilakukan oleh Wdiharih, et al. ${ }^{[11]}$.

Pada makalah ini model Michaelis Menten yang akan digunakan mempunyai bentuk sebagai berikut:

$$
y=\frac{\theta_{3} x}{\theta_{2}+x}+\varepsilon, \quad \theta_{2}, \theta_{3}>0, x \in[0, b]
$$

Model Emax yang digunakan mempunyai bentuk sebagai berikut:

$$
y=\frac{\theta_{3} x^{\theta_{4}}}{\theta_{2}+x^{\theta_{4}}}+\varepsilon, \quad \theta_{2}, \theta_{3}>0, \theta_{4} \geq 1, x \in[0, b]
$$

dengan asumsi $\varepsilon$ merupakan variabel acak dengan rata-rata nol dan variansi konstan $\sigma^{2}$. Berdasarkan model pada Persamaan (1) dan (2) akan ditentukan titik-titik rancangan D-optimal dengan program Matlab yang berupa M-file untuk mendefinisikan fungsi sasaran, menentukan titik-titik rancangan, menentukan matriks informasi dan inversnya serta untuk mengkonstruksikan grafik dari fungsi variansi terstandar.

\section{Deskripsi Teoritis.}

Model nonlinear yang digunakan mempunyai bentuk $y=\eta(x, \beta)+\varepsilon$. Rancangan dengan $\mathrm{p}$ buah titik rancangan dinotasikan:

$$
\xi=\left(\begin{array}{llll}
x_{1} & x_{2} & \ldots & x_{p} \\
w_{1} & w_{2} & \ldots & w_{p}
\end{array}\right)
$$

dengan: $\quad w_{i}=\frac{r_{i}}{n}$

$r_{i}$ : banyaknya ulangan untuk titik rancangan $x_{i}$

$n$ : banyaknya pengamatan dan $n=\sum_{i=1}^{p} r_{i}$

$\sum_{i=1}^{p} w_{i}=1$

Matriks informasi dari rancangan (3) adalah : 


$$
M(\xi)=\sum_{i=1}^{d} w_{i} h(x) h^{T}(x)
$$

merupakan matriks simetri berukuran $k x k$ dengan $k$ adalah banyaknya parameter dalam model, dengan $h(x)=\left(\frac{\partial \eta(x, \beta)}{\partial \beta_{1}}, \frac{\partial \eta(x, \beta)}{\partial \beta_{2}}, \ldots, \frac{\partial \eta(x, \beta)}{\partial \beta_{k}}\right)^{T}$. Matriks informasi pada Persamaan (4) masih mengandung parameter. Dalam melakukan percobaan, peneliti telah mempunyai informasi tentang nilai parameter, sehingga bila nilai parameter dimasukkan pada Persamaan (4), determinan dari matriks informasi merupakan fungsi dengan peubah ganda dalam $x\left(x_{1}, x_{2}, \ldots, x_{p}\right)$. Fungsi dispersi (variansi terstandar) yang bersesuaian dengan rancangan $\xi$ adalah:

$$
d(x, \xi)=h^{T}(x) M^{-1}(\xi) h(x)
$$

Nilai dari variansi terstandar untuk rancangan $D$-optimal antara nol sampai dengan $k$ ( $k$ adalah banyaknya parameter dalam model) dan maksimum dari variansi terstandar terjadi pada titik-titik rancangan. Berikut definisi dari rancangan dengan kriteria D-optimal.

Definisi 1. Atkinson et al ${ }^{[1]}$

Kriteria D-optimal adalah kriteria yang diperoleh dengan cara meminimumkan $\Psi\{M(\xi)\}$ dengan: $\Psi\{M(\xi)\}=\log \left|M^{-1}(\xi)\right|=-\log |M(\xi)|$

Berdasarkan Definisi 1, kriteria D-optimal diperoleh dengan cara memaksimalkan $|M(\xi)|$. Untuk menunjukan bahwa rancangan $\xi$ seperti pada Persamaan (3) memenuhi kriteria D-optimal digunakan Teorema Equivalensi Tergeneral dari Kiefer and Wolfowitz ${ }^{[9]}$ berikut.

Teorema 1. Teorema Equivalensi Tergeneral Kiefer and Wolfowitz ${ }^{[9]}$

Tiga kondisi berikut adalah equivalen:

1. Rancangan $\xi^{*} \xi^{*}$ memaksimalkan $|M(\xi)|$

2. Rancangan $\xi^{*} \xi^{*}$ meminimumkan $\max _{x} d(x . \xi)$

3. $\max _{x} d(x . \xi)=k$, dengan $k$ adalah banyaknya parameter dalam model.

Secara ringkas Teorema Equivalensi Tergeneral dapat dinyakan sebagi berikut:

$$
\text { Rancangan } \xi^{*} \text { memaksimalkan } \mid M\left(\xi \mid \Leftrightarrow d(x, \xi)=h^{T}(x) M^{-1}(\xi) h(x) \leq k\right.
$$

Untuk menunjukkan bahwa rancangan $\xi$ seperti pada Persamaan (3) merupakan rancangan D-optimal dengan melakukan cheking bahwa terpenuhinya:

$$
d(x, \xi)=h^{T}(x) M^{-1}(\xi) h(x) \leq k
$$




\section{Hasil dan Pembahasan}

\subsection{Rancangan D-optimal Model Michaelis Menten.}

Model Michaelis Menten yang digunakan adalah:

$$
\begin{gathered}
y=\frac{\theta_{3} x}{\theta_{2}+x}+\varepsilon, \quad \theta_{2}, \theta_{3}>0, x \in[0, b] \\
\eta(x, \theta)=\frac{\theta_{3} x}{\theta_{2}+x}
\end{gathered}
$$

Turunan parsial dari $\eta(x, \theta)$ terhadap parameternya adalah:

$$
h(x)=\left(-\frac{\theta_{3} x}{\left(\theta_{2}+x\right)^{2}}, \frac{x}{\left(\theta_{2}+x\right)}\right)^{T}
$$

Grafik dari model Michaelis Menten untuk $\theta_{3}=1$ pada beberapa nilai $\theta_{2}$ seperti pada Gambar 1.

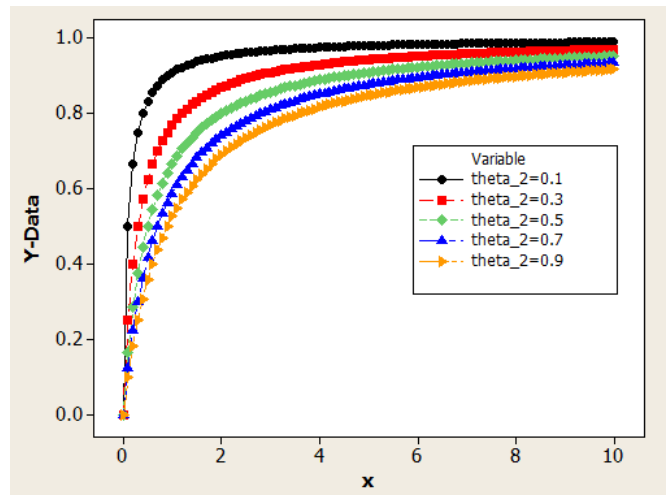

Gambar 1. Model Michaelis Menten untuk $\theta_{3}=1$ pada Beberapa Nilai $\theta_{2}$

Untuk menentukan rancangan D-optimal (menentukan titik-titik rancangan dan proporsinya sehingga terpenuhi kriteria D-optimal) dari model seperti Persamaan (1) dengan menggunakan Teorema berikut:

Teorema 2. (Widiharih, et al. ${ }^{[11]}$ ).

Rancangan D-optimal model Michaelis Menten merupakan rancangan minimal dengan titik-titik rancangan adalah: $x_{1}=\frac{\theta_{2} b}{2 \theta_{2}+b}, x_{2}=b$ dengan proporsi yang sama yaitu $\frac{1}{2}$.

Berdasarkan Teorema 2, karena menggunakan rancangan minimal maka:

$$
\xi=\left(\begin{array}{cc}
x_{1} & b \\
\frac{1}{2} & \frac{1}{2}
\end{array}\right)
$$


Elemen matriks informasi adalah:

$$
\begin{array}{ll}
m_{11}=\frac{1}{2} \sum_{i=1}^{2} \frac{\theta_{3}^{2} x_{i}^{2}}{\left(\theta_{2}+x_{i}\right)^{4}} & m_{22}=\frac{1}{2} \sum_{i=1}^{2} \frac{x_{i}^{2}}{\left(\theta_{2}+x_{i}\right)^{2}} \\
m_{12}=\frac{1}{2} \sum_{i=1}^{2} \frac{-\theta_{3} x_{i}^{2}}{\left(\theta_{2}+x_{i}\right)^{3}} & x_{2}=b
\end{array}
$$

Berdasarkan Teorema 1, dapat dibuat program Matlab untuk menenitukan titik-titk rancangan D-optimal dan cheking Teorema Equivalensi Tergeneral (Lampiran 1). Pada kasus $\theta_{2}=2,3262, \theta_{3}=25,3976$ dengan daerah rancangan $[0,1.5]$, diperoleh titik-titik rancangan $x_{1}=0,5671$ dan $x_{2}=1,5$.

Matriks informasi, invers matriks informasi dan fungsi dispersi (variansi terstandar) adalah:

$$
\begin{aligned}
M(\xi) & =\left(\begin{array}{cc}
4,8659 & -0,6787 \\
-0,6787 & 0,0961
\end{array}\right) \\
M^{-1}(\xi) & =\left(\begin{array}{cc}
14,2071 & 100,3838 \\
100,3838 & 719,6986
\end{array}\right) \\
d(x, \xi) & =h^{T}(x) M^{-1}(\xi) h(x) \\
& =\left(-\frac{25,3976 x}{(2,3262+x)^{2}} \frac{x}{(2,3262+x)}\right)\left(\begin{array}{cc}
14,2071 & 100,3838 \\
100,3838 & 719,6986
\end{array}\right)\left(\begin{array}{c}
-\frac{25,3976 x}{(2,3262+x)^{2}} \\
\frac{x}{(2,3262+x)}
\end{array}\right)
\end{aligned}
$$

Grafik dari fungsi variansi terstandar seperti pada Gambar 2 berikut:

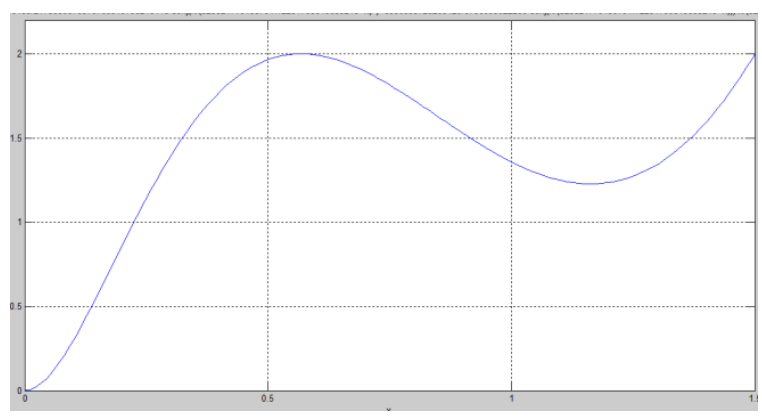

Gambar 2. Grafik $d(x, \xi)$ untuk Model (1) dengan $\theta_{2}=2,3262, \theta_{3}=25,3976$ pada Daerah Rancangan $[0,1.5]$

Berdasar Gambar 2, terlihat bahwa $d(x, \xi) \leq 2$ sehingga memenuhi Teorema Equivalensi Tergeneral, dapat disimpulkan titik-titik rancangan $x_{1}=0,5671$ dan $x_{2}=1,5$ merupakan titik-titik rancangan $D$-optimal model (1) dengan $\theta_{2}=2,3262, \theta_{3}=25,3976$ pada daerah rancangan $[0,1.5]$. 


\subsection{Rancangan D-optimal Model Emax.}

Model Emax yang digunakan adalah:

$$
\begin{aligned}
& y=\frac{\theta_{3} x^{\theta_{4}}}{\theta_{2}+x^{\theta_{4}}}+\varepsilon, \quad \theta_{2}, \theta_{3}>0, \theta_{4} \geq 1, x \in[0, b] \\
& \eta(x, \theta)=\frac{\theta_{3} x^{\theta_{4}}}{\theta_{2}+x^{\theta_{4}}}
\end{aligned}
$$

Turunan parsial dari $\eta(x, \theta) \eta(x, \theta)$ terhadap parameternya adalah:

$$
h(x, \theta)=\left(-\frac{\theta_{3} x^{\theta_{4}}}{\left(\theta_{2}+x^{\theta_{4}}\right)^{2}}, \frac{x^{\theta_{4}}}{\left(\theta_{2}+x^{\theta_{4}}\right)}, \frac{\theta_{2} \theta_{3} x^{\theta_{4}} \ln (x)}{\left(\theta_{2}+x^{\theta_{4}}\right)^{2}}\right)^{T}
$$

Grafik dari model Emax untuk $\theta_{2}=10,1385, \theta_{4}=2,3262$ pada beberapa nilai $\theta_{3}$ seperti pada Gambar 3.

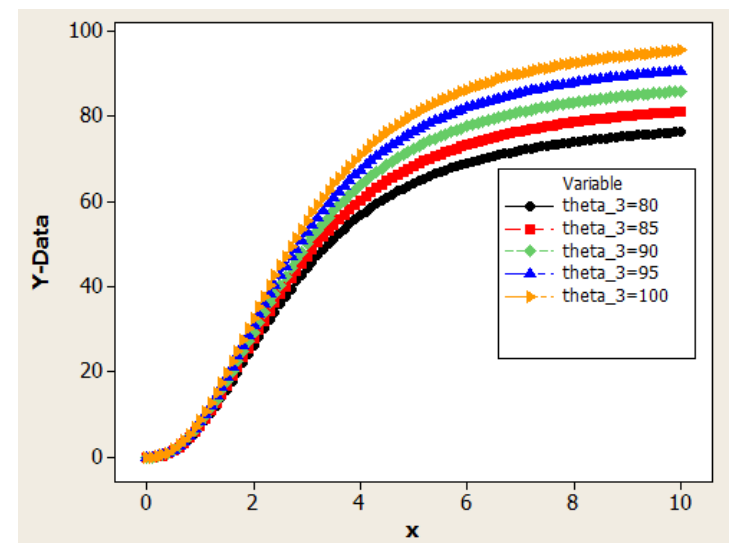

Gambar 3. Model Emax untuk $\theta_{2}=10,1385, \theta_{4}=2,3262$ pada Beberapa Nilai $\theta_{3}$

Untuk menentukan titik-titik rancangan $D$-optimal model EMAX menggunakan teorema berikut:

Teorema 3. (Widiharih, et al, ${ }^{[11]}$ ).

Rancangan D-optimal model EMAX merupakan rancangan minimal dengan titik-titik rancangan adalah $x_{1}, x_{2}$ dan $x_{3}=b$ dengan proporsi sama yaitu $\frac{1}{3}, x_{1}, x_{2}$, merupakan nilai yang memaksimumkan $|M(\xi, \theta)| \propto\left(x_{1} x_{2} x_{3}\right)^{2 \theta_{4}}(A+B)$, dengan:

$$
\begin{aligned}
& A=\sum_{i=1}^{3} \frac{\left(\ln \left(x_{i}\right)-\ln \left(x_{j}\right)\right)^{2}}{\left(\theta_{2}+x_{i}^{\theta_{4}}\right)^{4}\left(\theta_{2}+x_{j}^{\theta_{4}}\right)^{4}\left(\theta_{2}+x_{k}^{\theta_{4}}\right)^{2}} \\
& B=\sum_{i=1}^{3} \frac{\ln \left(x_{i}\right) \ln \left(x_{j}\right)+\ln \left(x_{i}\right) \ln \left(x_{k}\right)-\ln ^{2}\left(x_{i}\right)-\ln \left(x_{j}\right) \ln \left(x_{k}\right)}{\left(\theta_{2}+x_{i}^{\theta_{4}}\right)^{4}\left(\theta_{2}+x_{j}^{\theta_{4}}\right)^{3}\left(\theta_{2}+x_{k}^{\theta_{4}}\right)^{3}} \\
& i \neq j \neq k, \quad j, k=1,2,3, \quad x_{3}=b
\end{aligned}
$$


Berdasar Teorema 2 dapat diperoleh:

$$
\xi=\left(\begin{array}{ccc}
x_{1} & x_{2} & b \\
\frac{1}{3} & \frac{1}{3} & \frac{1}{3}
\end{array}\right)
$$

Elemen matriks informasi adalah:

$$
\begin{array}{ll}
m_{11}=\frac{1}{3} \sum_{i=1}^{3} \frac{\theta_{3} x_{i}^{2 \theta_{4}}}{\left(\theta_{2}+x_{i}^{\theta_{4}}\right)^{4}} & m_{22}=\frac{1}{3} \sum_{i=1}^{3} \frac{x_{i}^{\theta_{4}}}{\left(\theta_{2}+x_{i}^{\theta_{4}}\right)^{2}} \\
m_{33}=\frac{1}{3} \sum_{i=1}^{3} \frac{\theta_{2}^{2} \theta_{3}^{2} x_{i}^{2 \theta_{4}} \ln ^{2}\left(x_{i}\right)}{\left(\theta_{2}+x_{i}^{\theta_{4}}\right)^{4}} & m_{12}=\frac{1}{3} \sum_{i=1}^{3} \frac{-\theta_{3} x_{i}^{2 \theta_{4}}}{\left(\theta_{2}+x_{i}^{\theta_{4}}\right)^{3}} \\
m_{13}=\frac{1}{3} \sum_{i=1}^{3} \frac{\theta_{2} \theta_{3}^{2} x_{i}^{2 \theta_{4}} \ln \left(x_{i}\right)}{\left(\theta_{2}+x_{i}^{\theta_{4}}\right)^{4}} & m_{23}=\frac{1}{3} \sum_{i=1}^{3} \frac{\theta_{2} \theta_{3}^{2} x_{i}^{2 \theta_{4}} \ln \left(x_{i}\right)}{\left(\theta_{2}+x_{i}^{\theta_{4}}\right)^{3}}
\end{array}
$$

dengan $x_{3}=b$

Berdasarkan Teorema 3, dapat dibuat program Matlab untuk menentukan titik-titk rancangan D-optimal dan cheking Teorema Equivalensi Tergeneral (Lampiran 2). Pada kasus $\theta_{2}=10,1385, \theta_{3}=99,77242, \theta_{4}=1,008629$, diperoleh diperoleh titik-titik rancangan $x_{1}=2,1451, x_{2}=12,9973$ dan $x_{3}=50,0000$

Matriks informasi , invers matriks informasi dan fungsi dispersi (variansi terstandar) adalah:

$$
\begin{aligned}
& M(\xi)=10^{3}\left(\begin{array}{ccc}
0,0032 & -0,0009 & -0,0799 \\
-0,0009 & 0,0004 & 0,0274 \\
-0,0799 & 0,0274 & 2,3095
\end{array}\right) \\
& M^{-1}(\xi)=\left(\begin{array}{ccc}
2,3606 & -3,0995 & 0,1184 \\
-3,0995 & 44,4450 & -0,6350 \\
0,1184 & -0,6350 & 0,0121
\end{array}\right) \\
& d(x, \xi)=h^{T}(x) M^{-1}(\xi) h(x) \\
& =\left(\begin{array}{cccc}
-\frac{\theta_{3} x^{\theta_{4}}}{\left(\theta_{2}+x^{\theta_{4}}\right)^{2}} & \frac{x^{\theta_{4}}}{\left(\theta_{2}+x^{\theta_{4}}\right)} & \frac{\theta_{2} \theta_{3} x^{\theta_{4}} \ln (x)}{\left(\theta_{2}+x^{\theta_{4}}\right)^{2}}
\end{array}\right)\left(\begin{array}{ccc}
2,3606 & -3,0995 & 0,1184 \\
-3,0995 & 44,4450 & -0,6350 \\
0,1184 & -0,6350 & 0,0121
\end{array}\right)\left(\begin{array}{c}
-\frac{\theta_{3} x^{\theta_{4}}}{\left(\theta_{2}+x^{\theta_{4}}\right)^{2}} \\
\frac{x^{\theta_{4}}}{\left(\theta_{2}+x^{\theta_{4}}\right)} \\
\frac{\theta_{2} \theta_{3} x^{\theta_{4}} \ln (x)}{\left(\theta_{2}+x^{\theta_{4}}\right)^{2}}
\end{array}\right)
\end{aligned}
$$

dengan: $\theta_{2}=10,1385, \theta_{3}=99,77242, \theta_{4}=1,008629$

Grafik dari fungsi variansi terstandar seperti pada Gambar 4 berikut: 


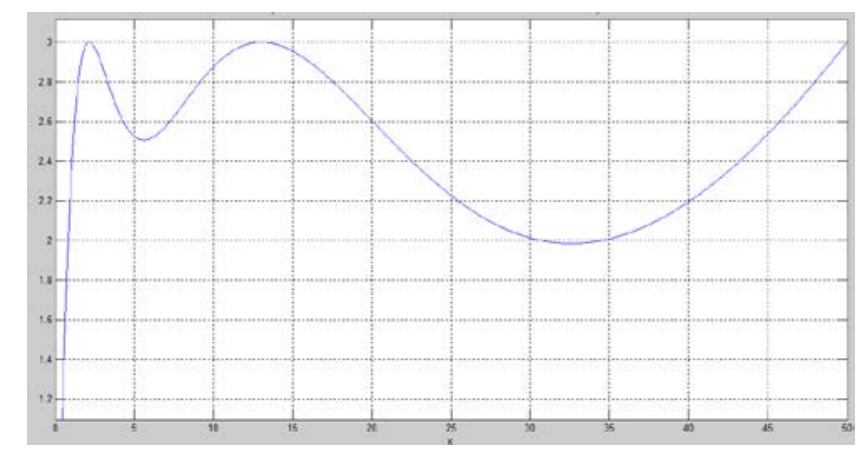

Gambar 4. Grafik $d(x, \xi)$ untuk Model (2) dengan $\theta_{2}=10,1385, \theta_{3}=99,77242, \theta_{4}=1,008629$ pada Daerah Rancangan $[0,50]$

\section{Kesimpulan}

Berdasarkan Teorema 2 dan 3, penentuan rancangan D-optimal model Michaelis Menten dan Emax mempunyai bentuk yang rumit. Determinan matriks informasi mempunyai bentuk yang kompleks, penentuan titik maksimum dari determinan matriks informasi tidak bisa dilakukan secara langsung. Pendekatan numeris sebagai alternatif dari masalah optimasi, dalam hal ini digunakan program Matlab untuk memudahkan para pengguna.

\section{DAFTAR PUSTAKA}

1. Atkinson, A.C., Donev, A.N. and Tobias, R.D., Optimum Experimental Designs, with SAS, OXFORD University Press, 2007.

2. Dette, $\mathrm{H}$ and Pepelyshev, A., Efficient Experimental Designs for Sigmoidal Growth Models. Journal of Statistical Planning and Inference, 2008, 138: 2-17.

3. Fang, X., and Hedayat, A.S., Locally D-optimal Designs Based on a Class of Compossed Models Resulted from Blending Emax and One-compartment Models, The Annals of Statistics, 2008, Vol.36, No.1: 428-444.

4. Li,G., and Majumdar, D., D-optimal Designs for Logistic Models with Three and Four Parameters, Journal of Statistical Planning and Inference, 2008, 138: 190-1959,.

5. Li, G., Optimal and Eficient Designs for Gompertz Regression Models. Ann Inst Stat Math, DOI 10.1007/s10463-011-03040-y, 2011

6. Li, G., and Balakrishnan, N., Optimal Designs for Tumor Regrowth Models, Journal of Statistical Planning and Inference, 2011, 141: 644-654.

7. Holford, N., Pharmacodynamic Principles and the Time Course of Immediate Drug Effect, Department Pharmacology and Clinical Pharmacology, University of Auckland, New Zeland, 2013.

8. Jericevic, Z.,and Kuster, Z., Nonlinear Optimization of Parameters in Michaelis Menten Kinetics, Croatia Chemica Acta CCACCAA, 2005, Vol. 78, No. 4: 519-523.

9. Kiefer, J., and Wolfowitz, J., The Equivalence of Two Extremum Problems, Can. Jnl. Math, 1960, Vol. 12: 363-36.

10. Scwhabe, R., Optimal Design for Linear and Nonlinear Models, A Short Course. Otto von Guerike University Magdeburg, July 2008, 21-25.

11. Widiharih,T., Haryatmi,S., dan Gunardi., D-optimal designs for Morgan Mercer Flodin (MMF) Models without Intercept , International Journal of Applied Mathematics and Statistics, 2015a, Vol.53, No. 5:163-171. 
Rancangan D-Optimal ... (Tatik W.)

12. Widiharih,T., Haryatmi,S., dan Gunardi., D-optimal designs for Morgan Mercer Flodin (MMF) Models With Three Parameters, Proceeding AIP, SEAMS UGM 2015b. 
Lampiran 1. Program Matlab Untuk Menentukan Rancangan D-optimal Model Michaelis Menten.

Model Michaelis Menten yang digunakan dalam program : $y=\frac{b x}{a+x}$

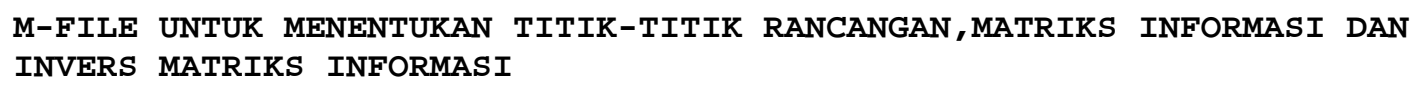

\% bbx : batas bawah dari $\mathrm{x}$ $\%$ bax : batas atas dari $\mathrm{x}$ $\%$ bby : batas bawah dari y $\%$ bay : batas atas dari y

\% masukkan nilai a

\% masukkan nilai b 


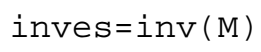

\% bbx : batas bawah dari x $\%$ bax : batas atas dari $\mathrm{x}$ 